with the working of the scheme as a whole. If, on the one hand, any but curable cases are refused admittance, the most dangerous and pitiful cases are left at large to injure others and to suffer alone ; whilst if nothing but advanced cases are admitted the colony at once becomes a hospital- nursing staff, hospital accommodation, expenses all increasing out of proportion to the good effected-and the colony, instead of taking its place in a well-rounded scheme, becomes a hospital for incurables, a home for the hopeless, and a place to be avoided by the hopeful, with the great moral elements of hope and encouragement essential to success for the treatment of all tuberculous patients completely eliminated.

Natnrally, it is a source of intense satisfaction to us that the $£ 75,000$ voted by the British Red Cross Society to her sister society in France is being devoted by that society to the provision of a colony for the treatment and training of tuberculous soldiers - a colony to be laid down and administered on similar lines to those on which the Papworth Colony is run.

\section{COLONIES FOR CONSUMPTIVES.}

BY NOEL DEAN BARDSWELL, M.Y.O., M.D. EDIN., F.R.C.P. LOND.

LATE MEDICAL SUPERINTENDFNT, KING EDWARD VII. SANATORIUM MEDICAL ADTISER TO INSURANCE COMMITTEE FOR COUNTT OF HONDON.

BroADLX speaking, there are two alternative policies relative to the treatment of the consumptive worker : either the patient must be kept at an institution until he is cured and can return with reasonable confidence to his former life and employment-this may be a matter of years-or, following a shorter course of sanatorium treatment, we must so change his environment as to render his conditions at home and at work such that recovery from tuberculosis is possible. It is the realisation of these facts that has led to the evolution of after-care organisations and, more recently, to the conception of colonies for consumptives.

The Two Types of Consumptize Colony.

The term "colony" is used to describe two types of institutions. These two colony schemes, though having much in common, present certain distinctive features which sharply differentiate the one from the other,

Soheme 1, associated with the name of Sir Robert Philip, provides for an institution for the exclusive reception of the early and most curable cases, with a view to giving them prolonged treatment and a training in some agricultural employment. Though linked up with the sanatorium from which the colonists are drawn and with the other elements of a comprehensive anti-tubercuiosis administration, it is designed as a separate institution. Equipped upon simpler lines than a sanatorium, it is less costly to administer. Moreover, the patients, by performing useful work in the institution and in the grounds, gardens, and farm, are able to reduce somewhat the cost of their maintenance. To give the favourable case some 12 or 18 months' institutional treatment in place of the more usual period of three to four months should, apart from any question of re-education, appreciably improve his outlook. The patient returns home, having made substantial progress on the road to recovery. With some after-care he may be expected, in many instances, to attempt successfully a return to his ordinary life and employment.

Scheme 2 is more comprehensive in scope, in that it makes provision for all kinds of cases, irrespective of the extent and character of their disease. Thus it comprises, under the same administration, a sanatorium, a colony as in Scheme 1 for vocational training, and a home for advanced cases. The opportunity for occupation and vocational training, however, is not limited to the most favourable cases, but is offered to every patient who desires it ańd who has a prospect of some degree of restoration of working capacity. Further, recognising that many patients can never be so restored to health as to be able to hold their own in the open labour market, the colony seeks to establish suitable trades and industries which, by offering remunerative employment under favourable conditions, will not only give scope for re-education, but encourage the permanent settlement in the neighbourhood of the colony of ex-patients and their families, thus forming the nucleus of a community living under the healthy conditions of a garden city. It is hoped that by this means the voluntary segregation of the consumptive will gradually be achieved.

This type of colony owes its inception to.Professor Sims Woodhead and Dr. P. C. Varrier-Jones, and it is upon these principles, just briefly outlined, that the Settlement at Papworth is now being developed, under the care of these two pioneer workers. The experiment of Papworth cannot fail to be most instructive. Should it prove that the setting up of industries for the employment of consumptives is a practical proposition, a vista of great possibilities will be opened up.

Experience of Sanatoriums in the Colony Principle.

Hitherto, for lack of money, neither prolonged treatment nor re-education has been possible except on a modest scale. What these measures might effect if adopted systematically is therefore, to some extent, a matter of speculation. However, many sanatoriums present striking examples of the efficacy of suitable employment under favourable conditions among their personnel. To name two institutions-at Peppard Common over 50 per cent., and at Nayland 70 per cent., of the staff are made up of former patients. These individuals are all earning their livelihoods. Some are on the permanent staff, to all appearances cured, others will remain for a year or two, then to return to the outside world; others again will remain indefinitely, performing work within their capacity, partially disabled for all time, but still useful members of society.

Similarly, after-care organisations furnish many instances of the maintenance of health and capacity for work by consumptives for whom healthy and sufficiently remunerative employment has been secured. That the principles underlying the colony idea are sound need not be insisted upon it is rather a question as to how far they can be put into practice on a large scale.

$$
\text { Experience of Existing Colonies. }
$$

As yet colonies in the country are too recently establishea to provide data of much value. None the less, the experience of a few institutions is sufficient to give some idea of the probable usefulness of colonies, and of the lines upon which these institutions may best be promoted.

The Edinburgh Colony.-The Springfield Colony, near Edinburgh, was organised by Sir R. Philip and opened in 1910 .

The colony consists of a mansion house and 30 acres of land, comprising two acres of fruit and vegetable garden, a poultry farm, pig-rearing department, and a mixed farm of 12 acres. There is accommodation for 25 patients, who under the direction of the resident staff, assist in the various activities of the colony:

Data kindly given me by Sir $R$. Philip relative to the period 1910 to 1914 show that during these years 88 patients transferred from the associated sanatorium passed through the colony, the average length of stay being some 12 months. Of this number, 11 on their discharge changed their employment for work other than on the land. Nine returned to their former occupation, 20 returned to work on or in connexion with the land, mostly in the colonies, 2 were taken on to the colony staff, and 5 female patients emigrated, domestic service seemingly being the occupation usually followed. The remaining patients returned home but to no stated occupation.

The condition of these 88 patients in 1917, exclusive of 4 who had been dismissed from the colony and 6 who have been lost sight of, was as follows: Well and in full work, 44 ; in poor health, 4 ; died of injuries or disease contracted on active service, 3 ; died of tuberculosis, 25 ; died, cause not stated, 2.

The Leicester Colony. - The experiments in this colony, carried out under the direction of Dr. Killick Millard, medical officer of health of the city of Leicester, date from 1914.

The 1914 scheme consisted in the placing during the summer months of a small number of convalescent sana. torium patients upon a large nursery in Derbyshire, practically a summer camp. Though on a smail scale, the experiment was a success. The patients all benefited greatly, and allowing for the inoome they earned by their work on the nurseries the cost of their maintenance worked ont at approximately $11 s$. a week.

By the 1916 and 1917 schemes convalescent male patients were employed under a skilled gardener in a large fruit and vegetable garden within easy access of the sanatorium. Though living within the sanatorium precincts, the colonists, limited in number to 20 , were accommodated in a separate pavilion and followed a different routine from in a separate pavilion and followed a different routine from
that of the patients in the main sanatorium. In particular 
they enjoyed the privilege of being allowed to go home at week-ends. The average stay at the colony worked out at three months. It was found difficult to persuade the most suitable of the sanatorium patients-namely, the ablebodied, to enter and remain in the colony, the men preferring to retarn to work at which they could earn a high wage. Clinically the results were most satisfactory. Financially, the cost of maintaining the patients in the colony department was the same as the weekly cost ruling in a sanatorium, the return from the colonists work being sufficient approximately to pay the wages of the skilled instructor.

Fayland Sanatorium and Colony.-At this institution, conducted by Dr. Jane Walker, a good deal of pioneer work upon colony lines has been carried out during the 16 years of its existence.

Although essentially a sanatorium, the work at Nayland has always been governed by the desire to promote the interests of the patient after his discharge from the sanatorium. As previously stated, every available post on the staff is filled by an ex-patient. Some of these former patients thus employed in the institution live in a hostel some distance from the sanatorium, and form the aucleas of a settlement. With regard to employment and vocational training, apart from instruction in gardening and vegetable growing no attempt is made to give an agricultural training. However, the sanatorium possesses a mixed farm of 200 acres, should the future see any demand for a training for the land. Considerable attention has been devoted to handicraft. At the present time there is provision for instruction in carpentry, toy-making, and bootrepairing for men, and for dressmaking and embroidery for women. These facilities are open to all the patients. Another feature which has a distinct value as an education is the sanatorium shop run on the lines of a village store. Here patients can learn the management of a small village business. More definitely upon colony lines is the dressmaking shop in the neighbouring village of Nayland staffed by four former sanatorium patients, and the school of highgrade metal craft recently established in the same village. This latter technical training colony is accommodated in pjctaresque premises, equipped with admirably fitted workrooms, formerly a leather factory. It accommodates 25 patients, who will be taught an interesting and remunerative trade. Certainty of employment is assured to the proficient by the Artificers' Guild, with which this enterprise is closely identified. Mention also should be made of the department for the treatment and education of tuberculous children, which forms another interesting feature of $\mathrm{Dr}$. Walker's establishment.

The Papworth Colony, near Cambridge.-The Papworth Colony, directed by Dr. Varrier-Jones, is a development of the earlier enterprise carried out at Bourn. Its characteristic features have already been referred to.

The colony comprises a large mansion, with grounds of 16 acres, which include a large walled-in kitchen garden and orchard, and 100 acres of agricultural land. The mansion is devoted to administrative purposes and to the accommodation of advanced cases. Accommodation for the more favourable cases is furnished by shelters built in the grounds. To provide means of useful employment for the patients, a carpenter's shop, forge, and mechanical workshops are in course of construction. Already the carpenter's department is well developed, and is in a position to execute orders for open-air shelters and other portable wooden strue-

tures. This department is managed by an ex-patient. a skilled carpenter, and is run on business lines; the actual work is carried out entirely by the patients. The making of parts for the Cambridge Scientific Instrument Company is another enterprise which has passed the experimental stage. Opportunity for the employment of some women patients is supplied by a neighbouring fruit and jam-making industry. rhe gardens and land offer an agrieultural training to those who elect for it. With a view to the permanent settlement of ex-patients the colony has acquired some model cottages formerly occupied by employees on the estate; the erection of farther cottages will be the work of the patients. Already applications by former patients for cottages exceed the available accommodation.

The Einson Colony, Banrnemouth.-This colony, under the management of the $Y . M . C . A_{\text {, }}$ is a unique experiment in that it offers facilities for a complete training extending over a period of at least 12 months in small-holding management and intensive culture.

Admission is limited strictily to fully convalescent patients who, while resident in a sanatorium, have proved them selves equal to at least six hour' manual work daily. TThere is accommodation for 21 colonists. The work is directed by an honorary resident superintendent, a gentleman of long experience of farming. Dr. E. H. Greves, of Bournemouth, acts as honorary vigiting physician. Some difficulty has been experienced in obtaining the full complement of 21 colonists: the length of the training required and the uncertainty of employment subsequently would appear to be the chief deterrents. Further, the physical standard required of candidates is a high one and excludes many would-be colonists.

The Hairmyres Colony. Lanarkshire, N.B.-Though not yet fully organised, the Hairmyres Colony demands notice, since it is the most ambitious scheme yet projected.

The colony is intended for the after-treatment and train. ing in an outdoor occupation of favourable cases and for the treatment and education of children. The colony, situated within easy access of Glasgow, extends to 200 acres. The buildings, which are well advanced in con struntion, will accommodate approximately 50 men, 50 women, and 50 children. A model farm and the best possible equipment for training in poultry-keeping, fruit and vegetable growing in short, all kinds of agriculture and horticulture-are being provided. A noticeable feature is the Associated School of Forestry, at which suitable patients will receive a thorough training in theoretical and practical forestry. Each department of the colonists? activities will be in charge of a skilled foreman. Dr. A. H. McPherson, under whose care the colony is developing, will be responsible for its general direction.

Space will not permit of reference to other colony undertakings.

The Financial Aspect of Colmies.

Running expenses. - It has been shown that an institution for convalescent patients can be run at a lower cost per head than a sanatorium. Simple accommodation and equipment and quite a small staff are sufficient; moreover, the labour of the colonists can contribute considerably to the running and upkeep of the establishment. Apart from thus reducing current expenses, it has not been demonstrated that patients by their work can add appreciably to the income of the colony, much less render the institution selfsupporting. At the Edinburgh Colony the cost per head of 20 patients for the year 1915-16 worked out at $22 s$. a week. A Coppings Green Market Garden Colony, managed by Dr.J.E. Chapman, in 1906, the cost per bed per week of 25 patients was $21 s$. Under peace conditions the cost of maintenance per head at a colony should not exceed approximately $20 \mathrm{~s}$. and wight well be a lower sum. That efficient treatment can be given at a low cost has been proved conclusively.

Capital cost. - The capital cost of colony schemes varies enormously, depending upon their scope.

The Hairmyres scheme has been budgeted for at some $£ 100,000$. The Edinburgh Colony cost approximately $£ 4000$ to establish. The cost of the proposed colony at Hull is estimated at $£ 10,000$, inclusive of the purchase of freehold, adaptation, equipment, and endowment; the colony will accommodate at least 35 patients. In respect to purchase, a capacious house, two cottages, buildings, and other outoffices, with 29 acres of land, valued at $£ 3750$, have been purchased by Sir James Reckitt and placed at the disposal of the Hull Tuberculosis After-care Committee, with option to purchase at any time for the sum of $\$ 2000$.

The capital cost of the origiual colony at Bourn for 15 patients was a rental of $\$ 20$ a year for the main building and 10 ncres of land and $£ 400$ for alterations and additional buildings. The Coppings Green Colony for 25 patients was established on a similar economical basis, the rent of the buildings and 10 acres of land having been $\$ 20$ per annum, and the cost of alterations and equipment having been covered by an outlay of $\$ 400$. The Y.M.C.A. Colong for 21 patients, complete with buildings, including farm buildings, equipment, and 30 acres of freehold land, cost $\$ 4000$.

At Nayland the premises which comprise the colony for technical training are rented for $\$ 80$ a year, and the sum of $£ 300$ has covered the cost of equipment. The instructor receives a salary of $90 \mathrm{~s}$. a week.

At this moment, when labour and material are scarcely to be obtained, the most economical method of establishing a colony is by renting and adapting suitable premises, as has been done at Bourn and Nayland.

Experience shows that a colony can be run with equal success as a distinct institution or as a department of an existing sanatorium. A colony on the Papworth principle could be built up round the nucleus of a sanatorium. A distinct advantage in grafting a colony on to an existing institution is that thereby an experienced medical staff is immediately available, and that various essentials, such as light, drainage, power, water, transport, \&c., are already provided for. It is necessary that the work of the patients, 
whether on the land or in workshops, be directed by wholetime skilled officers, since the medical superintendent is too occupied to spare the time for teaching, even should he possess the requisite knowledge.

\section{The Probable Rote of the Colony.}

It is the general experience that few things are more difficult than satisfactorily to change a consumptive patient's occupation. Light employment requiring little training is usually ill-paid, and in consequence unsuited to anyone with dependants. For the more skilled trades, which command a good wage, long training and experience are necessary. It can readily be understood, then, how that the most successful efforts of after-care organisation have been associated with the principle of enabling the patient to follow his usual occupation, or something akin to it, under reasonably healthy conditions:

Hitherto the training given to patients in a sanatorium has been valuable, chiefly as providing an interest, and thus relieving the monotony of a somewhat stereotyped routine. Comparatively rarely has a patient been enabled to earn his livelihood in a new calling learnt at the sanatorium. In the past most success has followed the training of patients as chanffeurs, but in future this arenue of employment seems likely to be closed.

It seems probable, therefore, that colonies will achieve more in virtue of the prolonged treatment they will give than as the result of their facilities for vocational training. So far as the civilian is concerned, vocational training cannot meet with any great measure of success unless it be accompanied by the provision of employment for those trained. This truth is reflected in the suggestion of sanatorium workshops and factories in connexion with certain trades which would permit of consumptive employees following their usual occupation under favourable conditions.

With regard to agriculture, it is the general experience that farming operations are too skilled and too arduous to be suited to many patients, although they are admirably adapted to the treatment of the more robust; moreover, few individuals born and bred in a town take kindly to a rural life. Except in the case of institutions serving rural areas, more may be expected from handicrafts than from agriculture in the way of re-education. Every institution, however, should be able to give the townsman some practical knowledge of kitchen gardening and allotment culture.

Financial Aspect of Colonies from standpoint of Patient.

Hitherto the work of the colonies and of sanatorinms has been handicapped by the fact that, owing to lack of means, patients with dependants cannot afford to remain away from home for long periods. At Edinburgh the colonists during 1910-14 were limited almost entirely to the unmarried. Latterly the depleted labour market has made it possible for even the less fit to obtain profitable employment. It is not easy for the able-bodied consumptive to acquiesce in working at a colony for no wage, while a good income awaits him outside. The Leicester Colony was forced to close in 1916 on this account. The future may well see the payment of a wage to patients in a colony, a principle which has been adopted at some colonies in Germany.

Unless arrangements can be made for the care of dependants it is difficult to see how, in the cases of civilians, prolonged treatment and training can be made possible except on a small scale. Some form of subsidy will be needed to render the principle capable of general application. The discharged service man in enjoyment of a pension is much better situated. The fact that he can leave home in the knowledge that his dependants are provided for gives him advantages which the civilian has never enjoyed. There exists, therefore, an exceptional opportunity for testing the feasibility of subsidised training and treatment, an opportunity which it is to be hoped will be fully exploited, since the results cannot fail to be of far-reaching importance.

UNIVERSITY OF LONDON, Of the 57 successful candidates at the recent Second Examination for Medical Degrees, Part II., 35 were women and 22 men. Of the former 29 were students at the London (R.F.H.) School of Medicine for Women (two of these also studied at other schools), 4 at King's College, London, 2 at University College, Cardiff, and 1 each at Cambridge and Manchester Universities.

\section{THE RAPID CURE OF HYSTERICAL SYMPTOMS IN SOLDIERS.}

BY A. F. HUPST, M.A. M.D. Oxon., F.R.C.P.,

TEMPORARY MAJOR, R.A.M.C.; PHYSICLAT AND NEUROLOGIST, GUY'S HOSPITAL; OFFICER IN CHARGE OF SEALE HAYNE MILITARY HOSPITAI, NEWTON ABBOT. AND

J. L. M. SYMNS, M.A., M.D. CANTAB.

CATTAIN, B.A.MI.C. (T.) ; NEUBOLOGIST, SEALE HAYNE MIIITABY HOSPITAL.

INCREASED experience in the treatment of the hysterical symptoms which form one of the largest classes of war neuroses bas led to gradual simplification of methods and increasing certainty and rapidity of cure.

\section{Earlier Experiences.}

From the earliest days of the war we realised that recent cases could generally be cured quickly and completely by a variety of methods, including simple persuasion and reeducation, suggestion with the aid of electricity in the waking state, and suggestion under hypnosis or light anæsthesia. But occasionally improvement was slow and incomplete. and when patients reached us after being under treatment for long periods in other hospitals we did not expect such good results.

Even in hysterical aphonia and mutism, which almost invariably disappeared after a few minutes' treatment, sometimes after lasting for a year or more, the more serious speech defect was often followed by a stammer, which might require careful re-education for several weeks before complete recovery occurred. Indeed, we regarded stammering as one of the conditions in which a rapid cure was rarely possible even in early cases.

Another condition of this sort was tremor: we were confirmed in this conclusion by the opinions which had been expressed by two such distinguished neurologists as Babinski in Paris and Oppenhein in Berlin, both of whom regarded the tremor of soldiers as a special neurosis of emotional origin, which differed from hysterical symptoms in being much less amenable to psychotherapy. We were fortunately less influenced by the writings of Babinski and Froment on reflex neuroses, acceptance of which would lead to the belief that contractures associated with vasomotor and secretory changes are not hysterical and could at the best improve very slowly with physicotherapy.

During the last few months we have come to realise that stammering and tremor, except the fine tremor of the hands and head in pure neurasthenia and hyperthyroidism, and all the cases we have seen which corresponded with Babinski and Froment's description of reflex contractures, are as amenable to treatment as hysterical mutism, aphonia and paralysis, and that they are undoubtedly of pure hysterical origin.

\section{Rupid Cure.}

Our more recent experience has shown that the prolonged re-education which we had thought was required to convert into a cure the great improvement of hich followed the active treatment of long-standing cases directly after admission is unnecessary, and we are now disappointed if complete recovery does not occur within 24 hours of commencing treatment, even in cases which have been in other hospitals for over a year.

If a man with severe hysterical paraplegia of many months duration is taught to walk in half an hour, and treatment is then discontinued on account of his fatigue, although his gait is stiff and nnsteady, he wîl probably not walk normally until he has undergone re-éducation for several weeks. But if the officer in charge not only ignores the patient's fatigue, but also his own, and continues the treatment for another half-hour or hour, or even for two or three hours, the patient will end by walking with a normal gait, although, of course, some time will elapse before he completely regains his strength. In the same way a mute or aphonic soldier, who stammers on recovering his voice, should not be left until the stammer is also cured, or be will only recover completely after receiving daily lessons for some weeks.

It is thus not merely in casualty clearing stations that immediate recoveries should occur in the vast majority of cases, but they should occur with equal frequency in hospitals in England. Unfortunately, the hysterical nature of many cases is not always recognised, and patients are 